\title{
KOMPETENSI PEMIMPIN DALAM MENGHADAPI THE ABUNDANCE ERA
}

\author{
Fery Wahyu Ramadhan ${ }^{1}$ \\ ${ }^{1}$ Mahasiswa Ilmu Perpustakaan, Universitas Negeri Malang \\ ferywahyu958@gmail.com
}

\begin{abstract}
ABSTRAK
Pemimpin merupakan seorang yang bertugas dan mempunyai kewajiban untuk mengatur berjalannya sebuah organisai agar bisa membangun dan menjadi organisasi yang sesuai dengan visi dan misi organisasi tersebut. Saat ini merupakan era revolusi industri 4.0. yakni era dimana semua serba cepat dan serba canggih sehingga masyrakat dapat mengakses informasi dengan cepat dan dimana saja. Terdapat empat prinsi era revolusi industri 4.0 yakni interkoneksi, transparansi informasi, bantan teknik serta keputusan terdesentralisasi. Era abudance ditandai dengan beberapa faktor yakni digitalisasi, deception, disrupsi, dematerilization, demonetization, democratization. Model kepeminpinan yang bisa diterapkan pada era abundance ialah model pemimpin yang memiliki perencanaan pandangan kedepan untuk institusinya yaitu transformasi. Kelebihan dari model ini adalah pemikiran yang kritis sehingga menimbulkan sebuah inovasi terus menerus yang bisa diimplemetasikan pada institusinya sehingga bisa bertahan dari perubahan era yang sangat cepat ini. kelemahannya ialah tuntutan dari pemimpin harus diiringi dengan dukungan baik itu moril (regulasi) dan dana yang berlimpah dikala ingin mewujudkan sebuah perpustakaan yang selalu mengikuti teknologi ini.
\end{abstract}

Kata Kunci: Revolusi industri, era keberlimpahan, kepemimpinan

\begin{abstract}
The leader is a person in charge and should regulate the running of an organization so that it can build and become an organization that is following the vision and mission of the organization. At present, it is the era of industrial revolution 4.0 namely, an era where everything is fast and sophisticated so that people can access information quickly and everywhere. There are four principles of the industrial revolution 4.0 era, namely interconnection, information transparency, technical assistance, and decentralized decisions - the era of abundance characterized by several factors, namely digitalization, deception, disruption, dematerialization, demonetization, democratization. The leadership model that can apply in the era of abundance is a model of a leader who has a forward-looking plan for his institution, namely transformation. The advantage of this model is that it is critical thinking that creates a continuous innovation that can be implemented in its institutions so that it can withstand the rapid changes of this era. His weakness is that demands from leaders must be accompanied by support both morally (regulation) and abundant funds when wanting to create a library that always follows this technology.
\end{abstract}

Keywords: industrial revolution, the era of abundance, leadership 


\section{PENDAHULUAN}

Pemimpin merupakan seorang yang bertugas dan mempunyai kewajiban untuk mengatur berjalannya sebuah organisai agar bisa membangun dan menjadi organisasi yang sesuai dengan visi dan misi organisasi tersebut. Kesuksesan organisasi bukan hanya pada kinerja dari para stafnya namun juga yang terpenting pada faktor kompetensi yang dimliki oleh pemimpin tersebut. Pada saat ini kita memasuki era revolusi industri, dimana sudah merambah era revolusi industri 4.0. Diera ini semua serba cepat dan serba canggih dimana kita dapat mengakses informasi dengan cepat dan dimana saja. Seorang pemimpin pun harus bisa mengikuti perkembangan zaman saat ini agar bisa memimpin suatu organisasi dengan baik sehingga organisasi itu bisa maju dan berkembang sesuai dengan visi dan misi organisasi tersebuh. Era digital juga bisa di sebut revolusi industri 4.0 yaitu merupakan sebuah istilah industri, bisa di sebut juga revolusi digital karena semua terjadi dan dilakukan di dunia maya dengan di tandai dengan terjadi proliferasi computer dan otomatisasi pencatatan di semua bidang. Dikatakan juga era disprupsi karena otomatisasi dan konektivitas sebuah bidang akan membuat pergerakan dunia industri dan persiangan kerja menjadi tidak linear. Artificial Intelegence (AI) merupakan salah satu karakteristik implementasi kecerdasan buatan. (Tjandrawinata, 2016). Saat ini seorang pemimpin harus arif dan bijak serta harus mempunyai kualifikasi yang baik dan bisa memanfaatkan sebuah kemajuan teknologi seperti Artificial Intelegence (AI) yang diimplementasikan di dunia perpustakaan khususnya dan umumnya di hal layak umum. Keterampilan seorang pemimpin juga diasah baik bersifat teknis maupun bukan, seperti mengorganisir sumber daya manusia yang dimiliki pada suatu organisasi agar bisa berjalan maksimal dan bisa membuat pola kerja yg efektif tapi membuat dampak yang baik dihapadan para pengguna. Perpustakaan sendiri berada di dua sisi yaitu sisi baik atau buruk dengan adanya revolusi industri ini. Untuk sisi baik yang didapatkan dengan adanya revolusi industri ini perpustakaan bisa mengembangkan dan mengkolaborasikan semua aspek baik layanan teknis mauppun non teknis dengan kemajuan teknologi serba tidak nampak (invisible) contoh adanya aplikasi perpustakaan yang ada pada penyedia aplikasi pada android dan apple yaitu Play store dan Apple Store. Kenapa demikian? karena masyarakat saat ini dihadapkan pada kondisi serba cepat dan instan, cepat dalam pelayanan yang artinya proses dalam pelayanan itu cepat dan prosedur yang mudah. Sering kali masyarakat pun geram ketika adanya pelayanan yang 
membutuhkan waktu lama padahal bisa dilakukan dengan cepat.

\section{PEMBAHASAN}

\subsection{Revolusi Industri 4.0}

Sejarah revolusi industri dimulai dari industri 1.0, 2.0, 3.0, hingga industri 4.0. Fase industri merupakan real change dari perubahan yang ada. Industri 1.0 ditandai dengan mekanisasi produksi untuk menunjang efektifitas dan efisiensi aktivitas manusia, industri 2.0 dicirikan oleh produksi massal dan standarisasi mutu, industri 3.0 ditandai dengan penyesuaian massal dan fleksibilitas manufaktur berbasis otomasi dan robot. Industri $4.0 \quad$ selanjutnya hadir menggantikan industri 3.0 yang ditandai dengan cyber fisik dan kolaborasi manufaktur (Hermann et al,2015; Irianto, 2017). Istilah industri 4.0 berasal dari sebuah proyek yang diprakarsai oleh pemerintah Jerman untuk mempromosikan komputerisasi manufaktur (Muhammad Yahya,2018).

Lee dkk (2013) menjelaskan bahwa revolusi industri 4.0 bisa ditandai dengan adanya peningkatan digitalisasi manufaktur dengan beberapa faktor pndorong yaitu :
- Adanya peningkatan volume data,kekuatan komputasi dan konektivitas.

- Kemunculan analisis, kemampuan dan kecerdasan bisnis

- Adanya bentuk interaksi baru antara manusia dan mesin.

- Adanya perbaikan instruksi transfer digital ke dunia fisik seperti robotika dan 3D Printing.

Lifter dan Tschiener (2013) menambahkan, prinsip dasar industri 4.0 adalah penggabungan mesin, alur kerja, dan sistem, dengan menerapkan jaringan cerdas di sepanjang rantai dan proses produksi untuk mengendalikan satu sama lain secara mandiri. Hermann et al (2016) menambahkan, ada empat desain prinsip industri 4.0. Pertama, interkoneksi (sambungan) yaitu kemampuan mesin, perangkat, sensor, dan orang untuk terhubung dan berkomunikasi satu sama lain melalui Internet of Things (IoT) atau Internet of People (IoP). Prinsip ini membutuhkan kolaborasi, keamanan, dan standar. Kedua, transparansi informasi merupakan kemampuan sistem informasi untuk menciptakan salinan virtual dunia fisik dengan memperkaya model digital dengan data sensor termasuk analisis data 
dan penyediaan informasi. Ketiga, bantuan teknis yang meliputi; (a) kemampuan sistem bantuan untuk mendukung manusia dengan menggabungkan dan mengevaluasi informasi secara sadar untuk membuat keputusan yang tepat dan memecahkan masalah mendesak dalam waktu singkat; (b) kemampuan sistem untuk mendukung manusia dengan melakukan berbagai tugas yang tidak menyenangkan, terlalu melelahkan, atau tidak aman; (c) meliputi bantuan visual dan fisik. Keempat, keputusan terdesentralisasi yang merupakan kemampuan sistem fisik maya untuk membuat keputusan sendiri dan menjalankan tugas seefektif mungkin.

Setiap orang mempunyai potensi kepemimpinan dalam dirinya (Born), potensi untuk memimpin setiap orang berbeda dengan segala kelebihan dan kekurangannya untuk menghadapi segala konteks dan tantangan semakin meningkat yang diperlukannya pengembangan, artinya kebutuhan dan kemauan belajar harus tinggi dan ditanamkan secara penuh kepada individu seseorang (horizontal) maupun diatasnya lagi akuntable terhadap program kepemimpinan (vertical). Seperti di perpustakaan pun semua hal itu diterapkan agar bisa memjadi seorang pemimpin yang baik dan memiliki kompetensi baik. Kemajuan teknologi tang sangat memicu seorang pemimpin harus menanggapinya dengan arif juga harus memanfaatkan kemajuan ini. Teknologi informasi memiliki dua efek yaitu baik dan buruk. Kita bisa memanfaatkan dan merubah teknologi menjdi hal positif. Sedangkan apabila kita tidak bisa memanfaatkannya maka kita akan tertinggal karena teknologi perkembangannya sangat pesat sekali. Hal senada juga dikemukakan oleh Mullins dalam jurnal karya Fridayana Yudiaatmaja (2013) yang menyatakan bahwa manajemen berhubungan dengan perencanaan, pengorganisasian, pengarahan, dan pengendalian aktivitasaktivitas yang dilakukan oleh bawahannya. Sedangkan kepemimpinan lebih semangat bawahan agar bertindak secara maksimal untuk suatu tujuan. Hollingsworth mengemukakan perbedaan mendasar antara manajemen dan kepemimpinan (Mullins, 2005), yaitu:

1. Seorang manajer melakukan administrasi, sedangkan seorang pemimpin melakukan inovasi.

2. Seorang manajer memelihara apa yang ada, sedangkan seorang pemimpin membangun apa yang diperlukan.

3. Seorang manajer fokus pada sistem dan struktur, sedangkan 
seorang pemimpin fokus pada pelakunya.

4. Seorang manajer melakukan pengawasan, sedangkan pemimpin membangun kepercayaan.

5. Seorang manajer melihat hal-hal yang detail, sedangkan pemimpin melihat hal-hal yang umum atau menyeluruh.

6. Seorang manajer melakukan segala sesuatunya dengan benar, sedangkan pemimpin memilih apa yang semestinya dilakukan.

Robi syahadah (2018) dalam artikelnya berdasarkan riset Harvard University, Carnegie

Foundation dan Stanford research center menyimpulkan bahwa $15 \%$ sukses dalam pekerjaan datang dari teknikal skill dan pengetahuan dan $85 \%$ dari soft skill yang di develop dengan baik dan kemampuan people skills. Melihat tren digital yang semakin meningkat saat ini ada 5 alasan mengapa soft skill semakin penting, yaitu:

1. Teknikal skill tanpa soft skill menjadi kurang bermanfaat Produk Knowlegde hebat menjadi tidak berarti tanpa communication skill.
2. Soft skill lebih sulit dipelajari teknikal skill lebih mudah dipelajari dan cepat terlihat hasilnya, harus sadar kemampuan soft skill saat ini masih rendah dan butuh.

3. Lingkungan kerja modern membutuhkan Softskill Kolaborasi, networking, interaksi dan suasana yang mendukung kreatifitas dan inovasi. Sangat diperlukan dalam konteks bisnis.

4. Customer membutuhkan soft skill Bersaing di Keunggulan produk dan harga mudah di tiru, kedekatan hubungan, trust, pelayanan yang jadi pembeda.

5. Era digital semakin membutuhkan soft skill Akan semakin banyak manual menjadi otomatis, perkerjaan diambil alih oleh teknologi, Soft- skill lah pembedanya.

Pemimpin harus mempunyai 3 soft skill yaitu Complex Problem Solving, Critical Thinking dan Creativity (Balance Right and Left Brain Function) untuk menghadapi era revolusi industri 4.0 ini. Softskill yang harus di miliki adalah sebagai berikut: 
1. Complex Problem Solving

2. Critical Thinking

3. Creativity

4. People Management

5. Coordinating with Others

6. Emotional Intelligence

7. Judgment and Decision Making

8. Service Orientation

9. Negotiation

10. Cognitive Flexibility

\subsection{Era Abundance}

Seiring berjalannya waktu pada saat ini kita sudah menuju ke Era Abundance ( Era Keberlimpahan). Menurut teori dari Peter Diamandis (Co-founder dari Singularity University) Era keberlimpahanpada saat ini sudah ditandai oleh perubahan besar yaitu :

1. Digitalisasi atau Digitalization Perubahan yang semula analog menjadi digital seperti musik yang dulunya berbentuk fisik sekarang berbentuk digital seperti Mp3, Mp4 dan lain-lain.

2. Deception atau Muslihat Adanya titik lonjak yang sebelumnya linier sehingga banyak merubah stigma masyarakat. Seperti dlu ditemukannya foto digital menggunakan teknologi amatir yang sudah mutakhir seperti kodak yang memiliki resolusi 0,1 megapixel sekarang sudah berkembang dan membuat kodal sendiri kewalahan akan kemajuan teknologi sehingga mengalami bangkrut.

3. Disruption atau Gangguan

Adanya gangguan terhadap fenomena yang sudah ada yang di pengaruhi oleh perkembangan teknologi sehingga yang berkembanglah yang akan bersaing. Seperti pada saat ini berkomunikasi bisa memakai Whatsapp yang dulunya memakai telepon umum.

4. Dematerialization atau Dematerialisasi

Perkembangan material yang ada kearah yang semakin maju. Contoh dulu penyimpanan computer harddisk IBM pada tahun 1956 dengan ukuran sebesar lemari yang memiliki penyimpanan sebesar 5MB sekarang sudah berkembang ke arah yang minimalis dan kecil namun memiliki daya tamping yang besar seperti Flashdisk.

5. Demonetization atau Demonetisasi ( Semakin Murah)

Semakin tidak adanya bentuk fisik yang digantikan oleh bentuk digital maka harga yang digunakan untuk memperolehnya semakin murah seperti perbandingan buku digital 
yang murah berbanding dengan buku fisik yang mahal karena ada faktor biaya cetak.

\section{Democratization atau Demokrasi}

Seluruh elemen masyarakat memperoleh manfaat dari adanya perkembanngan teknologi yang ada sehingga bisa membuat paradigma baru yaitu siapa yang tidak bisa mengikuti maka akan tertinggal bahkan bangkrut (perusahaan). Salah satu caranya berudah mengikuti perubahan atau mati dengan konsep lama.

Implementasi dari 10 aspek dan 6 faktor adanya era abundance diatas berada di sosok Ridwan Kamil. Pada awal menjabat, Ridwan Kamil meluncurkan inovasi program yang sangat dibutuhkan serta bisa di dapat secara cepat. Contoh program yang diluncurkannya ialah program Jabar Quick Respone oleh pemerintah daerah Jawa Barat, sebagai salah satu sarana untuk memperoleh informasi secara cepat dan di tuntut untuk cepat dalam meresponnya. Jabar Quick Response ini tersedia di beberapa platform seperti Instagram, Whatsapp, dan Website.

Seorang pemimpin perpustakaan pun harus membuat sebuah inovasi yang bisa membuat sebuah organisasi yang di pimpinnya itu maju. Di era disrupsi ini yang semua hal dsajikan cepat dan efisien seorang pemimpin bisa membuat sebuah inovasi pencarian informasi yang satu pintu namun pemustaka bisa mengakses yang diinginkannya, seperi membuat sebuah terobosan sebuah aplikasi berbasis web dan android sehingga pemustaka bisa mencari informasi tersebut dengan tepat dan perpustakaan ikut terlibat kerjasama dengan institusi lain seperti Dinas Kesehatan, Dinas Pariwisata dan lainnya. Jenis informasi yang disajikan berupa referensi yang bersifat mendasar. Contoh Dinas Hukum dan Ham mengenai UU yang berkaitan dengan permasalahan masyarakat seperti HAM. Itu bisa menjadi sebuah terobosan karena masyarakat cenderung ingin memcari informasi dengan cepat tapi informasi yang didapat sudah pasti validitasnya.

Model kepeminpinan yang bisa diterapkan pada era abundance ialah model pemimpin yang memiliki perencanaan pandangan kedepan untuk institusinya yaitu transformasi. Model ini cocok karena perubahan era yang sangat cepat yang ditandai denga teknologi yang semakin maju sehingga sosok pemimpin haru berfikir kedepan agar perpustakaan bisa bertahap setiap zaman. Kelebihan dari model kepeminpinan ini adalah pemikiran yang kritis sehingga menimbulkan sebuah 
inovasi terus menerus yang bisa diimplemetasikan pada institusinya sehingga bisa bertahan dari perubahan era yang sangat cepat ini, adapun kelemahannya ialah tuntutan dari pemimpin harus diiringi dengan dukungan baik itu moril (regulasi) dan dana yang berlimpah dikala ingin mewujudkan sebuah perpustakaan yang selalu mengikuti teknologi ini.

\section{KESIMPULAN}

Seorang pemimpin harus memiliki kualifikasi kompetensi yang menyesuaikan denga era pada saat ini, karena ada sebuah pergeseran dan perubahan perilaku masyarakat yang sudah menggunakan gawainya. Oleh karena itu seorang pemimpin harus memiliki inovasi sehingga masyarakat bisa berkembang dan mengikuti era saat ini yang serba cepat. Sebuah inovasi berupa kegiatan maupun platform bisa diciptakan untuk mendukung eksistensi perpustakaan dengan mengemas informasi dengan menarik sehhingga masyarakat tertarik dan ingin berkunjung ke perpustakaan. Pemimpin harus memiliki pemikiran kritis terhadap kejadian yang ada disekitarnya kemudian menuangkannya pada inovasi serta adanya kolaborasi antara semua lini perpustakaan sehingga bisa mencapai tujuan bersama.

\section{DAFTAR PUSTAKA}

Gorton,Ceri.Digital Leadership :

Leadership And Resilience In The

Uk's Cultural Sector. Makalah

disajikan sebagai Laporan triwulan.

( https://www.cerigorton.io/s/Ceri-

Gorton-Digital-Leadership-Report-

dhr2.pdf ) (Online) Diakses pada

Maret 2016.

Syahadah,Robi. Melihat Konsep

Kepemimpinan Di Era Digital 4.0.

(https://pelatihanpengembangansd

m.co.id/konsep-kepemimpinan/)

diakses pada tanggal 29 September

2018 pada pukul 19.20.

Yahya,Muhammad. Era Industri 4.0-

Tantangan Dan Peluang

Perkembangan Pendidikan

Kejuruan Indonesia.Makalah

disajikan pada Orasi Ilmiah

Professor bidang Ilmu Pendidikan

Kejuruan Universitas Negeri

Makassar Tanggal 14 Maret 2018

yang diakses pada tanggal 29

September 2018.

Yudiaatmaja,Fridayana. Kepemimpinan:

Konsep, Teori Dan Karakternya.

Disajikan dalam bentuk jurnal

Media Komunikasi FIS Vol 12

Universitas Pendidikan Ganesha

Vol 12, No 2.Agustus 2013.

Zainuddin,Ahmad Faiz. 12 Januari 2018. Move-On Dari Era "Distruption", Menyongsong Era 
“Abundance".http://www.konfronta

si.com/content/opini/move-s-dari-

era-

\%E2\%80\%9Cdisruption\%E2\%80\%

9D-menyongsong-era-

$\%$ E2\%80\%9Cabundance\%E2\%80

\%9D ( Online) Diakses pada 21

November 2018. 
